\title{
Treatment and outcomes: medical and surgical treatment for intestinal Behçet's disease
}

\author{
Tadakazu Hisamatsu, Mari Hayashida \\ The Third Department of Internal Medicine, Kyorin University School of Medicine, Tokyo, Japan
}

Behçet's disease (BD) is a chronic relapsing disease involving multiple organ systems. BD is characterized clinically by oral and genital aphthae, cutaneous lesions, and ophthalmological, neurological, and/or gastrointestinal manifestations. It is widely recognized that the presence of intestinal lesions may be a poor prognostic factor in intestinal BD, increasing the risk of surgery and decreasing the quality of life. Despite this, the management of intestinal BD has not been standardized. Empirical therapies including 5-aminosalicylic acid and corticosteroids have been used anecdotally to treat intestinal BD, but recent studies have provided evidence for the efficacy of anti-tumor necrosis factor $\alpha$ monoclonal antibodies. The development of agents targeting tumor necrosis factor $\alpha$ continues, it seems likely that they will change the therapeutic strategy and clinical outcomes of intestinal BD and inflammatory bowel disease. Monitoring disease activity such as endoscopic evaluation will become more important to obtain better outcomes. Here, we review current and future perspectives in the treatment and outcomes of intestinal BD.

(Intest Res 2017;15:318-327)

Key Words: Intestinal Behçet's disease; Anti-TNF- $\alpha$ mAb; Mucosal healing

\section{INTRODUCTION}

Behçet's disease (BD) was first described in 1937 by Hulusi Behçet, a Turkish dermatologist, as a triad of recurrent aphthous stomatitis, genital aphthae, and relapsing uveitis. ${ }^{1}$ Although intestinal lesions associated with BD may cause serious complications, such as perforation, and decrease the patient's quality of life, the diagnosis and management of intestinal BD have not been standardized. Empirical therapies have been used anecdotally to treat intestinal BD. However, evidence is accumulating that anti-tumor necrosis factor

Received January 12, 2017. Revised March 19, 2017.

Accepted March 20, 2017. Published online May 22, 2017

Correspondence to Tadakazu Hisamatsu, The Third Department of Internal

Medicine, Kyorin University School of Medicine, 6-20-2 Shinkawa, Mitaka-

shi, Tokyo 181-8611, Japan. Tel: +81-422-47-5511 (ext. 5729), Fax: +81-

422-71-5381,E-mail: thisamatsu@ks.kyorin-u.ac.jp

Financial support: This work was supported in part by grants from the Japan Sciences Research Grant for Research on Intractable Diseases

(Japanese Inflammatory Bowel Disease Research Group and Behçet's Disease Research Committee) affiliated with the Japan Ministry of Health, Labour

and Welfare. Conflict of interest: None. $\alpha$ (anti-TNF- $\alpha$ ) monoclonal antibodies (mAbs) are effective treatments for this indication. In Japan, the anti-TNF- $\alpha$ mAbs, adalimumab (ADA) and infliximab (IFX), are both approved for the treatment of intestinal BD. The introduction of these agents may change our therapeutic strategy and make us reconsider conventional therapies for intestinal BD.

\section{MEDICAL TREATMENT}

\section{5-Aminosalicylic Acid}

Although there is little clinical evidence for its efficacy, 5-aminosalicylic acid (5-ASA) is used as an empirical therapy for intestinal BD (Table 1). Jung et al. ${ }^{2}$ retrospectively investigated the long-term clinical outcomes and predictors of clinical relapse in patients with intestinal BD receiving 5-ASA therapy. They found that for 143 patients who received 5-ASA therapy, the cumulative relapse rates at 1, 3, 5, and 10 years after remission were $8.1 \%, 22.6 \%, 31.2 \%$, and $46.7 \%$, respectively. In this study, younger age ( $<35$ years), higher CRP level ( $\geq 1.5 \mathrm{mg} / \mathrm{dL}$ ), and higher disease activity

๑ Copyright 2017. Korean Association for the Study of Intestinal Diseases. All rights reserved.

This is an Open Access article distributed under the terms of the Creative Commons Attribution Non-Commercial License (http://creativecommons.org/licenses/by-nc/4.0)

which permits unrestricted non-commercial use, distribution, and reproduction in any medium, provided the original work is properly cited. 
index for intestinal Behçet's disease (DAIBD) score $(\geq 60)$ were associated with a poor response to 5-ASA therapy. Hatemi et al. ${ }^{3}$ retrospectively reviewed the treatment of 60 BD patients with gastrointestinal lesions. In 16 patients with mild disease, 5-ASA was used as initial treatment. Sonta et al. ${ }^{4}$ reported an intestinal BD patient in whom 5-ASA was effective for the treatment of esophageal ulcers. These reports suggest that 5-ASA may have clinical efficacy as induction and maintenance therapy for intestinal BD; however, further studies, including placebo-controlled trials, are necessary to confirm this. In their consensus statement, Japanese experts recommended 5-ASA for induction therapy of patients with mild to moderate intestinal BD. ${ }^{5}$

\section{Corticosteroids}

To date, there have been no prospective studies demonstrating the clinical efficacy of corticosteroids in intestinal $\mathrm{BD}$, despite the fact that they have been used empirically for moderate to severe and refractory intestinal BD (Table 2). ${ }^{6-11}$ The Japanese consensus guideline recommends 0.5 to $1.0 \mathrm{mg} / \mathrm{kg} / \mathrm{day}$ of prednisolone for 1 to 2 weeks as induction therapy, followed by tapering at $5 \mathrm{mg} / \mathrm{wk}^{5,12,13} \mathrm{In}$ severe cases, an intravenous high dose of prednisolone $(1 \mathrm{mg} / \mathrm{kg})$ or methylprednisolone pulse ( $1 \mathrm{~g}$ /day for 3 days) can be used. ${ }^{14,15}$ Park et al. ${ }^{16}$ reported that clinical remission and response rates to corticosteroid therapy are $46 \%$ and $43 \%$,

Table 1. 5-Aminosalicylic Acid Treatment

\begin{tabular}{|c|c|c|c|}
\hline Author (year) & $\begin{array}{l}\text { Level of published } \\
\text { evidence }\end{array}$ & $\begin{array}{l}\text { No. of } \\
\text { patients }\end{array}$ & Outcome \\
\hline Sonta et al. (2000) & Case report & 1 & Mesalazine demonstrated clinical efficacy on esophageal ulcers \\
\hline Jung et al. $(2012)^{2}$ & $\begin{array}{l}\text { Retrospective (single } \\
\text { tertiary academic center) }\end{array}$ & 143 & $\begin{array}{l}\text { - Clinical relapse: } 32.2 \% \text { (relapse rates: } 1 \mathrm{yr}, 8.1 \% ; 3 \mathrm{yr}, 22.6 \% ; 5 \mathrm{yr}, 31.2 \% \text {; } 10 \mathrm{yr} \text {, } \\
46.7 \% \text { ) } \\
\text { - Poor response to 5-ASA therapy: younger age }<35 \mathrm{yr} \text {; CRP >1.5 mg/dL; DAIBD } \\
\text { score } \geq 60\end{array}$ \\
\hline Hisamatsu et al. $(2014)^{5}$ & $\begin{array}{l}\text { Japanese consensus } \\
\text { statements }\end{array}$ & - & $\begin{array}{l}\text { The optimal dose of 5-ASA for adult patients, } 2.25-3.00 \mathrm{~g} / \text { day. Sulfasalazine is } \\
\text { also used, the optimal dose is } 3-4 \mathrm{~g} / \text { day. }\end{array}$ \\
\hline Hatemi et al. $(2016)^{3}$ & $\begin{array}{l}\text { Retrospective } \\
\text { (multidisciplinary center) }\end{array}$ & 16 & $\begin{array}{l}10 \text { of } 16 \text { patients }(62.5 \%) \text { achieved remission and did not relapse during the } \\
89.3 \pm 64.5 \text { mo }\end{array}$ \\
\hline
\end{tabular}

5-ASA, 5-aminosalicylic acid; DAIBD, disease activity index for intestinal Behçet's disease.

Table 2. Corticosteroid Treatment

\begin{tabular}{|c|c|c|c|c|}
\hline Author (year) & $\begin{array}{l}\text { Level of published } \\
\text { evidence }\end{array}$ & $\begin{array}{l}\text { No. of } \\
\text { patients }\end{array}$ & Regimen & Outcome \\
\hline $\begin{array}{l}\text { Nakase et al. } \\
(2001)^{6}\end{array}$ & Case report & 1 & $\begin{array}{l}\text { PSL } 40 \text { mg+intravenous dexamethasone } 2.5 \text { mg } \\
\text { every } 2 \text { wk }\end{array}$ & $\begin{array}{l}\text { After } 4 \text { wk, the endoscopic findings of } \\
\text { cecal ulcer revealed healing }\end{array}$ \\
\hline $\begin{array}{l}\text { Toda et al. } \\
(2002)^{7}\end{array}$ & Case report & 1 & $\begin{array}{l}\text { PSL } 40 \text { mg+20 mg of prednisolones injections } \\
\text { into the superior and inferior mesenteric } \\
\text { arteries }\end{array}$ & $\begin{array}{l}\text { Multiple healing ulcers, but no open ulcers, } \\
\text { were observed between the rectum and } \\
\text { transverse colon } 12 \text { day after intra- } \\
\text { arterial prednisolone injection. }\end{array}$ \\
\hline $\begin{array}{l}\text { Yasuo et al. } \\
(2003)^{8}\end{array}$ & Case report & 1 & PSL 0.5 mg/kg & $\begin{array}{l}\text { The endoscopic findings of esophageal } \\
\text { ulcer revealed healing. }\end{array}$ \\
\hline $\begin{array}{l}\text { Park et al. } \\
(2010)^{16}\end{array}$ & Retrospective & 54 & $\begin{array}{l}\text { The median dosage of corticosteroid, } 0.58 \mathrm{mg} / \mathrm{kg} \\
(0.39-1.20 \mathrm{mg} / \mathrm{kg})\end{array}$ & \\
\hline $\begin{array}{l}\text { Hisamatsu et al. } \\
(2014)^{5}\end{array}$ & $\begin{array}{l}\text { Japanese consensus } \\
\text { statements }\end{array}$ & - & $\begin{array}{l}\text { Weight-based approach of } 0.5-1.0 \mathrm{mg} / \mathrm{kg} \text { per } \\
\text { day of prednisolone for } 1-2 \text { wk followed by a } \\
\text { taper of } 5 \mathrm{mg} \text { weekly until discontinuation. }\end{array}$ & - \\
\hline $\begin{array}{l}\text { Saleh and Arayssi } \\
(2014)^{15}\end{array}$ & Review & - & $\begin{array}{l}1 \mathrm{~g} \text { intravenous methylprednisolone infusions } \\
\text { daily for } 3 \text { day, followed by } 1 \mathrm{mg} / \mathrm{kg} / \text { day } \\
\text { prednisolone tapered slowly }\end{array}$ & - \\
\hline
\end{tabular}

PSL, prednisolone. 
respectively. However, 1 year later, $35.2 \%$ of patients who achieved clinical remission showed steroid dependency and $7.4 \%$ of patients had undergone surgery. Kimura et al. ${ }^{17}$ retrospectively reviewed 34 patients with intestinal $\mathrm{BD}$ and compared the characteristics of patients treated with corticosteroids and/or 5-ASA $(\mathrm{n}=8)$ with those of patients with refractory disease who required additional immunosuppressants, anti-TNF- $\alpha$ mAbs, or surgery $(n=12)$. In the refractory group, more ulcers outside the ileocecal region, more active intestinal bleeding, higher positivity for HLA-B51, higher blood CRP levels, and a higher white blood cell count at onset were observed. In particular, the presence of melena, expression of HLA-B51, or level of CRP $>4 \mathrm{mg} / \mathrm{dL}$ was identified as predictive factors for refractory $\mathrm{BD}$.

However, Takada and colleagues ${ }^{18,19}$ raised concerns about the use of corticosteroids in intestinal BD patients, and have also suggested that a low-residue diet may be an effective treatment.

\section{Immunomodulators}

Azathioprine and 6-mercaptopurine are widely used to treat patients with intestinal $\mathrm{BD}$, especially in moderate to severe or refractory disease (Table 3). Jung et al. ${ }^{20}$ retrospectively reviewed all patients with intestinal $\mathrm{BD}$ who received thiopurine therapy. Of a total of 272 patients, 67 (24.6\%) received their first course of thiopurine therapy at their center, and 39 of the 67 patients (58.2\%) received thiopurines for maintenance of clinical remission. The cumulative relapse rates at $1,2,3$, and 5 years after remission were $5.8 \%, 28.7 \%$, $43.7 \%$, and $51.7 \%$, respectively. Japanese consensus guidelines recommend thiopurines for patients with refractory intestinal BD, such as corticosteroid-dependent or corticosteroid-resistant patients. ${ }^{5}$ Hatemi et al. ${ }^{3}$ supported azathioprine as a good choice for first-line therapy, because $65 \%$ of their patients entered remission and did not relapse during the mean follow-up of nearly 6 years. Lee et al. ${ }^{21}$ reviewed a total of 77 patients with intestinal BD who received 5-ASA $(\mathrm{n}=50,64.9 \%)$ or thiopurine $(\mathrm{n}=27,35.1 \%)$ therapy after surgery. The postoperative recurrence rate was lower in pa-

Table 3. Immunomodulator Treatment

\begin{tabular}{|c|c|c|c|c|}
\hline $\begin{array}{l}\text { Author } \\
\text { (year) }\end{array}$ & $\begin{array}{l}\text { Level of } \\
\text { published } \\
\text { evidence }\end{array}$ & $\begin{array}{l}\text { No. of } \\
\text { patients }\end{array}$ & Regimen & Outcome \\
\hline $\begin{array}{l}\text { Hisamatsu } \\
\text { et al. }(2014)^{5}\end{array}$ & $\begin{array}{l}\text { Japanese } \\
\text { consensus } \\
\text { statements }\end{array}$ & - & AZA, 25-50 mg/day & $\begin{array}{l}\text { Japanese consensus statements (the } 2 \text { nd) recommended } \\
\text { thiopurines for refractory intestinal BD such as } \\
\text { corticosteroid-dependent or -resistant patients. }\end{array}$ \\
\hline $\begin{array}{l}\text { Park et al. } \\
(2015)^{23}\end{array}$ & Retrospective & 83 & $\begin{array}{l}\text { - } \mathrm{AZA}, 2.0-2.5 \mathrm{mg} / \mathrm{kg}(6-\mathrm{MP} \text { dose was } \\
\text { converted to equivalent AZA) } \\
\text { - Starting AZA/6-MP dose, } 1.0 \mathrm{mg} / \mathrm{kg} / \text { day }\end{array}$ & $\begin{array}{l}\text { Leukopenia (WBC count }<4,000 / \mu \mathrm{L} \text { ) during thiopurine } \\
\text { maintenance therapy was associated with prolonged } \\
\text { remission in patients with IBD and } \mathrm{BD} \text { during } 6 \text { yr. }\end{array}$ \\
\hline $\begin{array}{l}\text { Hatemi et al. } \\
(2016)^{3}\end{array}$ & Retrospective & 37 & AZA, $2.0-2.5 \mathrm{mg} / \mathrm{kg} / \mathrm{day}$ & $\begin{array}{l}65 \% \text { of patients obtained remission and did not relapse } \\
\text { during a mean follow-up of } 68.6 \pm 43.6 \text { mo. }\end{array}$ \\
\hline
\end{tabular}

BD, Behçet's disease; AZA, azathioprine; 6-MP, 6-mercaptopurine; 5-ASA, 5-aminosalicylic acid; WBC, white blood cell. 
tients who received thiopurines than in patients treated with 5-ASA $(P=0.050)$. The hazard ratio for recurrence was 0.636 (95\% CI, 0.130-1.016; $P=0.053$ ) for postoperative thiopurine compared with that for 5-ASA. However, the rates of reoperation, readmission, and death were not significantly different between the 5-ASA and thiopurine groups. In contrast, Choi et al. ${ }^{22}$ reported that the risk of reoperation was lower for patients who received azathioprine than for those who did not. Regarding predictive factors, Park et al. ${ }^{23}$ reported that leukopenia (white blood cell count, $<4,000 / \mu \mathrm{L}$ ) during thiopurine therapy was associated with prolonged remission in patients with IBD and BD.

In a study of immunomodulators other than thiopurines, Iwata et al. ${ }^{24}$ reported that combination therapy with IFX and methotrexate showed efficacy for refractory intestinal BD. Matsumura et al. ${ }^{25}$ reported a case of refractory intestinal BD that was successfully treated with oral tacrolimus.

\section{Thalidomide}

Thalidomide has been identified as an anti-inflammatory and immunomodulatory agent because of its inhibitory effect on TNF- $\alpha$. Although clinical evidence is lacking, thalidomide and its analog lenalidomide are sometimes used for the management of $\mathrm{CD}^{26-28}$ and there are several studies that report the efficacy of thalidomide in intestinal $\mathrm{BD}^{29-33}$ Travis et al. ${ }^{29}$ reported that thalidomide was used for maintenance therapy in patients treated with IFX. Terrin et al. ${ }^{30}$ also described a pediatric BD patient with diarrhea who was treated with thalidomide. In a report by Kari et al., ${ }^{31} 5$ pediatric BD patients were treated with thalidomide at $1 \mathrm{mg} / \mathrm{kg} / \mathrm{wk}$ to $1 \mathrm{mg} / \mathrm{kg} /$ day, resulting in complete remission in 3 patients and clinical response in 2. Sayarlioglu et al. ${ }^{32}$ reported a patient who required multiple surgeries due to intestinal perforations and was refractory to intense immunosuppressive therapies, including methylprednisolone and cyclophosphamide. Thalidomide (100 mg/day) was started after the third surgery, and the patient experienced no additional intestinal perforations during the follow-up period of 4 months.

Yasui et al. ${ }^{33}$ reviewed the cases of 7 patients with juvenileonset BD with severe, recurrent intestinal involvement. Thalidomide was started at $2 \mathrm{mg} / \mathrm{kg}$ per day followed by dose adjustment according to the initial response. All 7 patients showed dramatic improvement in clinical symptoms and they successfully discontinued corticosteroid therapy. Thus, there is evidence to support the clinical efficacy of thalidomide for intestinal BD, especially pediatric BD. Nevertheless, the evidence is still insufficient, and evidence from large co- hort and prospective studies is needed.

\section{Anti-TNF- $\alpha$ mAbs}

The use of anti-TNF- $\alpha$ mAb therapy for intestinal BD was first reported in 2001 by Hassard et al..$^{34}$ They treated a patient with steroid-dependent intestinal BD with 4 doses of IFX over a 6-month period. The CDAI score, used as a clinical parameter of disease activity, decreased from 270 points before infusion to 13 points by week 2 . With IFX, steroid-free remission was sustained. Endoscopic findings at 10 weeks after the first infusion showed marked improvement of intestinal lesions. ${ }^{34}$ Travis et al. ${ }^{29}$ reported the successful treatment of 2 patients having intestinal BD with IFX. Both cases were refractory to corticosteroids and other treatments, including thalidomide and cyclosporine. Within 10 days of IFX administration, the ulcers had healed and extraintestinal manifestations had improved. In these 2 patients, IFX was used as induction therapy, but not as scheduled maintenance therapy. Kram et al. ${ }^{35}$ described the successful treatment of a patient with 3 infusions of IFX at weeks 0,2 , and 6 , according to a regimen of induction therapy for CD.

Since these early reports, evidence of the therapeutic utility of anti-TNF- $\alpha$ mAb in intestinal BD has accumulated (Table 4). Early on, IFX was the anti-TNF- $\alpha$ mAb most frequently used in intestinal $\mathrm{BD},{ }^{36,37}$ with the exception of 1 patient treated with $\mathrm{ADA} .^{38}$ In addition, IFX was used as an episodic treatment or as induction therapy (at weeks 0,2 , and 6), ${ }^{29,34-37}$ but not as a scheduled maintenance therapy. However, after the establishment of a scheduled maintenance regimen of anti-TNF- $\alpha \mathrm{mAb}$ for CD (every 8 weeks), there were a number of reports of anti-TNF- $\alpha$ mAbs used for both induction and scheduled maintenance therapy in intestinal BD. Naganuma et al. ${ }^{39}$ reported on 6 Japanese patients with intestinal $\mathrm{BD}$, all of whom were steroid dependent and refractory to other treatments, who received IFX induction therapy ( $5 \mathrm{mg} / \mathrm{kg}$ at 0,2 , and 6 weeks), followed by maintenance therapy every 8 weeks. Four of the 6 patients achieved and maintained remission with IFX. Iwata et al. ${ }^{24}$ assessed the short- and long-term efficacy and safety of combination therapy with IFX and methotrexate in 10 patients with refractory intestinal BD. Gastrointestinal symptoms and disease-associated complications improved within 4 weeks in all patients, and ileocecal ulcers had disappeared in $50 \%(5 / 10)$ and $90 \%(9 / 10)$ of patients at 6 and 12 months, respectively. Maruyama et al. ${ }^{40}$ described a patient with steroid-refractory intestinal BD who was successfully maintained in clinical and endoscopic remission by an infusion of 


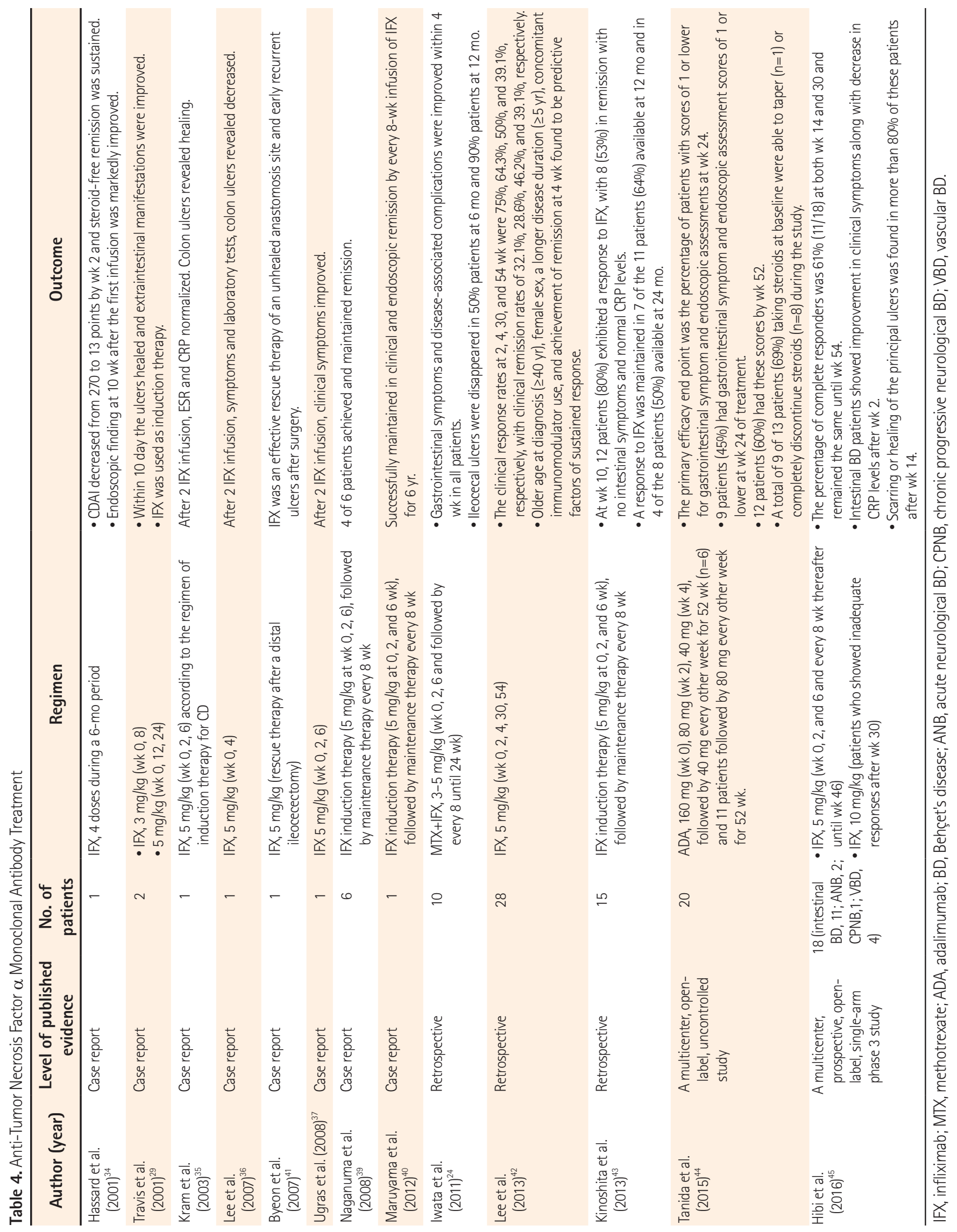


IFX ( $5 \mathrm{mg} / \mathrm{kg}$ ) every 8 weeks for 6 years. A retrospective noncontrolled review of the medical records of 28 patients with intestinal BD who received at least one dose of IFX in Korea identified clinical response rates of $75 \%, 64.3 \%, 50 \%$, and $39.1 \%$, and clinical remission rates of $32.1 \%, 28.6 \%, 46.2 \%$, and $39.1 \%$, at 2, 4, 30, and 54 weeks, respectively, after IFX infusion. ${ }^{42}$ In another study, 15 patients with active intestinal BD were treated with IFX ( $5 \mathrm{mg} / \mathrm{kg}$ every 8 weeks) at a single center. At week 10, 12 patients (80\%) exhibited a response to IFX; 8 (53\%) were in remission with no intestinal symptoms and normal CRP levels. A response to IFX was maintained in 7 of the 11 patients $(64 \%)$ available at 12 months and in 4 of the 8 patients (50\%) available at 24 months. ${ }^{43}$

A prospective clinical trial in Japan was started based on accumulating case reports of the efficacy of anti-TNF- $\alpha$ mAbs in patients with intestinal BD. This multicenter, openlabel, uncontrolled study aimed to evaluate the efficacy and safety of ADA in patients with intestinal BD who were refractory to corticosteroid and/or immunomodulator therapies. ${ }^{44}$ Twenty patients were administered $160 \mathrm{mg}$ ADA at the start of the study and $80 \mathrm{mg} 2$ weeks later, followed by $40 \mathrm{mg} \mathrm{ev}$ ery other week for 52 weeks. For some patients, the dose was increased to $80 \mathrm{mg}$ every other week. The primary efficacy endpoint was the percentage of patients with a score $\leq 1$ for gastrointestinal symptoms and endoscopic assessments at week 24 . This endpoint was reached by 9 patients (45\%) at week 24 of treatment, and by 12 patients $(60 \%)$ by week 52 . A total of 9 of 13 patients (69\%) taking steroids at baseline were able to taper $(\mathrm{n}=1)$ or completely discontinue steroids $(\mathrm{n}=8)$ during the study.

Following the clinical trial of ADA, a multicenter, prospective, open-label, single-arm, phase 3 study was performed to determine the efficacy, safety, and pharmacokinetics of IFX in BD patients with serious complications, including gastrointestinal, neurological, or vascular involvement, who had shown poor response or intolerance to conventional therapy. ${ }^{45}$ IFX was administered at weeks 0,2 , and 6 , and then every 8 weeks thereafter until week 46 . The dose was increased to $10 \mathrm{IFX} / \mathrm{kg}$ in patients who showed inadequate responses to IFX after week 30 . The percentage of complete responders (according to predefined criteria depending on the symptoms and results of ileocolonoscopy) at week 30 was defined as the primary endpoint. The percentage of complete responders was $61(11 / 18)$ at weeks 14 and 30 and remained the same until week 54 . With IFX, clinical symptoms dramatically improved and CRP levels decreased at week 2. Not only clinical symptoms, but also endoscopic findings rapidly improved. Scarring or healing of the prin- cipal ulcers was found in more than $80 \%$ of these patients after week 14. Collectively, these case reports and clinical trials provide evidence for the efficacy of anti-TNF- $\alpha$ mAbs in intestinal BD, at least for induction therapy. ADA and IFX efficacy was observed to be rapid by analysis of clinical, serological, and endoscopic endpoints. ${ }^{44,45}$ Although further evidence will be necessary, it is expected that both ADA and IFX will demonstrate long-term maintenance efficacy $y^{24,40,44,45}$ and endoscopically evident healing of ulcers. ${ }^{40,44,45}$

Anti-TNF- $\alpha$ mAbs have not yet been established as a postoperative therapy in patients with intestinal BD who have undergone bowel resection. Byeon et al. ${ }^{41}$ described a patient with intestinal BD who was successfully treated with IFX as rescue therapy for an unhealed anastomosis site and early recurrent ulcers after surgery.

There is no consensus about the concomitant use of immunomodulators and anti-TNF- $\alpha$ mAbs for intestinal BD, despite anecdotal evidence of its efficacy as induction and maintenance treatment. Even for CD, it remains unresolved whether anti-TNF- $\alpha$ mAbs should be used in combination with immunomodulators. ${ }^{46-50}$

Although one study reported the effectiveness of methotrexate plus IFX, ${ }^{24}$ another study described a patient who was successfully maintained with IFX monotherapy. ${ }^{40}$

\section{Mucosal Healing as a Predictive Marker for Long- Term Prognosis}

Intestinal BD is a progressive disease that causes dysfunction of the digestive tract and IBD. Postoperative disease recurrence is common, and multiple surgeries are often required in patients with refractory intestinal BD or CD. Since clinical symptoms and the clinical activity index of IBD are often subjective, discrepancies between clinical symptoms and endoscopic findings are often observed. To date, endoscopic findings have been considered the gold standard objective parameter for evaluation of IBD activity. Mucosal healing, defined as endoscopic remission, has become the goal of IBD treatment. Many retrospective studies have indicated that mucosal healing may predict better long-term prognosis, including maintenance of clinical remission, reduced risk of surgery, and reduced risk for the development of colon cancer. ${ }^{51}$ Although there is currently insufficient evidence, the concept of "mucosal healing" may also be applicable to the management of intestinal BD. Lee et al. ${ }^{52}$ reported that the discrepancy between the clinical activity index and endoscopic findings is observed not only in IBD but also in intestinal BD. Yim et al. ${ }^{53}$ retrospectively reviewed 
the medical records of 80 patients with intestinal BD who underwent colonoscopy within 3 months of clinical remission. At the time of clinical remission, 57 patients (71.3\%) had active ulcers and 23 patients (28.7\%) achieved mucosal healing. At the follow-up point, 39 patients $(68.4 \%)$ in the active ulcer group but only 7 (30.4\%) in the mucosal healing group experienced recurrence. The cumulative recurrence rate was significantly higher in the active ulcer group than in the mucosal healing group $(P<0.001)$, suggesting that mucosal healing could be a predictive factor for long-term prognosis in intestinal BD. Several case reports and 2 clinical trials (ADA and IFX) have shown that anti-TNF- $\alpha$ mAbs can induce and maintain mucosal healing in intestinal BD patients. ${ }^{40,44,45}$ Further prospective analyses will be necessary to prove that achievement of mucosal healing improves longterm prognosis in terms of a reduced clinical relapse rate and risk of surgery.

\section{SURGICAL TREATMENT}

\section{Risk of Surgery and Prognosis}

About $3 \%$ to $16 \%$ of patients with $\mathrm{BD}$ have gastrointestinal tract involvement. ${ }^{12}$ The natural history of intestinal BD has not been clearly delineated and it is difficult to predict which patients will experience a poor clinical course. In a retrospective review of 20 patients, Naganuma et al. ${ }^{54}$ reported that the presence of ocular and ileal lesions was a risk for surgery. Jung et al. ${ }^{55}$ evaluated the clinical course of 130 intestinal BD patients during the first 5 years after diagnosis, and found that the majority of patients $(74.6 \%)$ achieved remission or mild clinical activity at 5 years, whereas $16.2 \%$ had multiple relapses or chronic symptoms. Furthermore, the clinical course over the first year after diagnosis influenced the course in subsequent years. Patients in the severe clinical course group were younger, had lower albumin levels, and had higher ESR, CRP levels, and DAIBD scores than patients in the mild clinical course group.

Despite the evident benefits of medical therapy, intestinal BD patients sometimes require surgery and may experience postoperative disease recurrence. Intestinal BD is associated with complications such as intestinal perforation, bleeding, and abscess, and intestinal involvement is therefore a poor prognostic indicator for BD patients. Perforation and massive gastrointestinal bleeding are absolute indications for surgery, and abdominal abscess, fistula, and stricture should be considered as possible indications. Other surgery candidates are intestinal BD patients who are refractory to medical treatment, including corticosteroid and anti-TNF- $\alpha$ mAbs. However, surgery should be carefully considered in these patients because of the risk of postoperative recurrence. Thus, intestinal BD should be considered a progressive disorder, at least in a subpopulation of patients. Chung et al. ${ }^{56}$ performed a retrospective review of 93 patients with intestinal BD who received medical therapy, and found cumulative recurrence rates of $24.9 \%$ at 2 years and $43.0 \%$ at 5 years. The presence of gastrointestinal symptoms at the initial presentation was a risk for recurrence. Patients with volcano-type and deep intestinal ulcers, and those who failed to achieve complete remission during the initial treatment, also had a risk of recurrence. Cumulative rates for surgery were $6.7 \%$ at 2 years and $15.1 \%$ at 5 years. The typical type of ulcer was the only predictive factor for the likelihood of surgery. Moon et al. ${ }^{57}$ reviewed 129 patients with intestinal BD. Among them, 33 patients had intestinal perforations and all underwent emergent or elective laparotomy. Younger age ( $\leq 25$ years) at diagnosis, history of prior laparotomy, and volcano-shaped intestinal ulcers were identified as independent risk factors for free bowel perforation in these patients.

One concern about surgical treatment in intestinal BD patients is the risk for postoperative disease recurrence requiring repeat surgery. Iida et al. ${ }^{58}$ reported that postoperative recurrence of intestinal ulcers was observed in 7 of 9 patients who had undergone a total of 15 operations. Jung et al. ${ }^{59}$ reported that 42 (58.3\%) of 72 Korean patients who had undergone surgery experienced postoperative recurrence, with 22 (30.6\%) requiring reoperation. The cumulative 2and 5 -year recurrence rates after surgery were $29.2 \%$ and $47.2 \%$, respectively.

\section{Postoperative Treatment}

To date, a standard postoperative treatment strategy for intestinal BD patients has not been established. The clinical benefit of postoperative thiopurine therapy is controversial. Lee et al. ${ }^{21}$ reviewed the outcomes of 77 patients with intestinal BD and found lower postoperative recurrence rates in patients who were treated postoperatively with thiopurines, compared with those receiving 5-ASA. However, there were no significant differences in the rates of reoperation, readmission, or death between the 2 groups. In contrast, Choi et $\mathrm{al}^{22}$ reported that patients who received azathioprine postoperatively showed better clinical courses than those who did not. Thalidomide was also used as a postoperative therapy in a patient who required multiple surgeries. ${ }^{32}$ To date, there are no reports reviewing the efficacy of postoperative 
anti-TNF- $\alpha$ mAbs therapy in intestinal BD patients.

\section{FUTURE PERSPECTIVES}

Accumulating clinical evidence supports the efficacy of anti-TNF- $\alpha$ mAbs for intestinal BD and may change the therapeutic strategy for this disease. Most importantly, the natural history of refractory patients and their risk factors should be identified. The importance of endoscopic remission for monitoring disease activity has not been fully accepted in the management of intestinal BD, as it has for IBD. In addition, further clinical studies are necessary to evaluate immunomodulators and anti-TNF- $\alpha$ mAbs as maintenance therapy for intestinal BD. Postoperative management of intestinal BD also needs to be standardized, both to decrease the risk of repeat surgery and to improve the quality of life for postoperative patients.

\section{REFERENCES}

1. Behçet H. Über rezidivierende, aphthöse, durch ein Virus verursachte Geschwüre am Mund, am Auge und an den Genitalien. Dermatol Wochenschr 1937;105:1152-1157.

2. Jung YS, Hong SP, Kim TI, Kim WH, Cheon JH. Long-term clinical outcomes and factors predictive of relapse after 5-aminosalicylate or sulfasalazine therapy in patients with intestinal Behcet disease. J Clin Gastroenterol 2012;46:e38-e45.

3. Hatemi I, Esatoglu SN, Hatemi G, Erzin Y, Yazici H, Celik AF. Characteristics, treatment, and long-term outcome of gastrointestinal involvement in Behcet's syndrome: a strobe-compliant observational study from a dedicated multidisciplinary center. Medicine (Baltimore) 2016;95:e3348.

4. Sonta T, Araki Y, Koubokawa M, et al. The beneficial effect of mesalazine on esophageal ulcers in intestinal Behcet's disease. J Clin Gastroenterol 2000;30:195-199.

5. Hisamatsu T, Ueno F, Matsumoto T, et al. The 2nd edition of consensus statements for the diagnosis and management of intestinal Behçet's disease: indication of anti-TNFalpha monoclonal antibodies. J Gastroenterol 2014;49:156-162.

6. Nakase H, Okazaki K, Kawanami C, et al. Therapeutic effects on intestinal Behçet's disease of an intravenous drug delivery system using dexamethasone incorporated in lipid emulsion. J Gastroenterol Hepatol 2001;16:1306-1308.

7. Toda K, Shiratori Y, Yasuda M, et al. Therapeutic effect of intraarterial prednisolone injection in severe intestinal Behçet's disease. J Gastroenterol 2002;37:844-848.
8. Yasuo M, Miyabayashi H, Okano T, Aoki H, Ichikawa K, Hirose Y. Successful treatment with corticosteroid in a case of Behçet's syndrome with multiple esophageal ulcerations. Intern Med 2003;42:696-699.

9. Cheon JH, Kim WH. An update on the diagnosis, treatment, and prognosis of intestinal Behçet's disease. Curr Opin Rheumatol 2015;27:24-31.

10. Skef W, Hamilton MJ, Arayssi T. Gastrointestinal Behçet's disease: a review. World J Gastroenterol 2015;21:3801-3812.

11. Hisamatsu T, Naganuma M, Matsuoka K, Kanai T. Diagnosis and management of intestinal Behçet's disease. Clin J Gastroenterol 2014; 7:205-212.

12. Sakane T, Takeno M, Suzuki N, Inaba G. Behçet's disease. N Engl J Med 1999;341:1284-1291.

13. Kobayashi K, Ueno F, Bito S, et al. Development of consensus statements for the diagnosis and management of intestinal Behçet's disease using a modified Delphi approach. J Gastroenterol 2007;42:737-745.

14. Grigg EL, Kane S, Katz S. Mimicry and deception in inflammatory bowel disease and intestinal Behçet disease. Gastroenterol Hepatol (N Y) 2012;8:103-112.

15. Saleh Z, Arayssi T. Update on the therapy of Behçet disease. Ther Adv Chronic Dis 2014;5:112-134.

16. Park JJ, Cheon JH, Moon CM, et al. Long-term clinical outcomes after the first course of corticosteroid therapy in patients with moderate to severe intestinal Behget's disease. Gastroenterology 2010;138:S698-S699.

17. Kimura Y, Asako K, Kikuchi H, Kono H. Characteristics of patients with intestinal Behçet's disease requiring treatment with immunosuppressants or anti-TNFalpha antibody. Mod Rheumatol 2016;26:132-137.

18. Takada Y, Saigenji K. Is intestinal Behçet's disease in fact an enterocolitis or an ulcer disease, and is steroid treatment useful or harmful? J Gastroenterol 2003;38:1015-1016.

19. Takada Y, Fujita Y, Igarashi M, et al. Intestinal Behçet's disease: pathognomonic changes in intramucosal lymphoid tissues and effect of a "rest cure" on intestinal lesions. J Gastroenterol 1997;32:598-604.

20. Jung YS, Cheon JH, Hong SP, Kim TI, Kim WH. Clinical outcomes and prognostic factors for thiopurine maintenance therapy in patients with intestinal Behcet's disease. Inflamm Bowel Dis 2012;18:750-757.

21. Lee HW, Cheon JH, Lee HJ, et al. Postoperative effects of thiopurines in patients with intestinal Behçet's disease. Dig Dis Sci 2015;60:3721-3727.

22. Choi IJ, Kim JS, Cha SD, et al. Long-term clinical course and prognostic factors in intestinal Behçet's disease. Dis Colon Rectum 2000;43:692-700. 
23. Park MS, Kim DH, Kim DH, et al. Leukopenia predicts remission in patients with inflammatory bowel disease and Behcet's disease on thiopurine maintenance. Dig Dis Sci 2015;60:195-204.

24. Iwata S, Saito K, Yamaoka K, et al. Efficacy of combination therapy of anti-TNF-alpha antibody infliximab and methotrexate in refractory entero-Behçet's disease. Mod Rheumatol 2011;21:184-191.

25. Matsumura K, Nakase H, Chiba T. Efficacy of oral tacrolimus on intestinal Behcet's disease. Inflamm Bowel Dis 2010;16:188189.

26. Felipez LM, Gokhale R, Tierney MP, Kirschner BS. Thalidomide use and outcomes in pediatric patients with Crohn disease refractory to infliximab and adalimumab. J Pediatr Gastroenterol Nutr 2012;54:28-33.

27. Akobeng AK, Stokkers PC. Thalidomide and thalidomide analogues for maintenance of remission in Crohn's disease. Cochrane Database Syst Rev 2009;(2):CD007351. doi: 10.1002/14651858.CD007351.pub2.

28. Srinivasan R, Akobeng AK. Thalidomide and thalidomide analogues for induction of remission in Crohn's disease. Cochrane Database Syst Rev 2009;(2):CD007350. doi: 10.1002/14651858. CD007350.pub2.

29. Travis SP, Czajkowski M, McGovern DP, Watson RG, Bell AL. Treatment of intestinal Behçet's syndrome with chimeric tumour necrosis factor alpha antibody. Gut 2001;49:725-728.

30. Terrin G, Borrelli O, Di Nardo G, Pacchiarotti C, Cucchiara S. A child with aphthae and diarrhoea. Lancet 2002;359:316.

31. Kari JA, Shah V, Dillon MJ. Behçet's disease in UK children: clinical features and treatment including thalidomide. Rheumatology (Oxford) 2001;40:933-938.

32. Sayarlioglu M, Kotan MC, Topcu N, Bayram I, Arslanturk H, Gul A. Treatment of recurrent perforating intestinal ulcers with thalidomide in Behçet's disease. Ann Pharmacother 2004;38:808811.

33. Yasui K, Uchida N, Akazawa Y, et al. Thalidomide for treatment of intestinal involvement of juvenile-onset Behçet disease. Inflamm Bowel Dis 2008;14:396-400.

34. Hassard PV, Binder SW, Nelson V, Vasiliauskas EA. Anti-tumor necrosis factor monoclonal antibody therapy for gastrointestinal Behçet's disease: a case report. Gastroenterology 2001;120:995-999.

35. Kram MT, May LD, Goodman S, Molinas S. Behçet's ileocolitis: successful treatment with tumor necrosis factor-alpha antibody (infliximab) therapy: report of a case. Dis Colon Rectum 2003;46:118-121.

36. Lee JH, Kim TN, Choi ST, et al. Remission of intestinal Behçet's disease treated with anti-tumor necrosis factor alpha monoclonal antibody (Infliximab). Korean J Intern Med 2007;22:24-27.
37. Ugras M, Ertem D, Celikel C, Pehlivanoglu E. Infliximab as an alternative treatment for Behçet disease when other therapies fail. J Pediatr Gastroenterol Nutr 2008;46:212-215.

38. Ariyachaipanich A, Berkelhammer C, Nicola H. Intestinal Behçet's disease: maintenance of remission with adalimumab monotherapy. Inflamm Bowel Dis 2009;15:1769-1771.

39. Naganuma M, Sakuraba A, Hisamatsu T, et al. Efficacy of infliximab for induction and maintenance of remission in intestinal Behçet's disease. Inflamm Bowel Dis 2008;14:1259-1264.

40. Maruyama Y, Hisamatsu T, Matsuoka K, et al. A case of intestinal Behçet's disease treated with infliximab monotherapy who successfully maintained clinical remission and complete mucosal healing for six years. Intern Med 2012;51:2125-2129.

41. Byeon JS, Choi EK, Heo NY, et al. Antitumor necrosis factoralpha therapy for early postoperative recurrence of gastrointestinal Behçet's disease: report of a case. Dis Colon Rectum 2007;50:672-676.

42. Lee JH, Cheon JH, Jeon SW, et al. Efficacy of infliximab in intestinal Behçet's disease: a Korean multicenter retrospective study. Inflamm Bowel Dis 2013;19:1833-1838.

43. Kinoshita H, Kunisaki R, Yamamoto H, et al. Efficacy of infliximab in patients with intestinal Behçet's disease refractory to conventional medication. Intern Med 2013;52:1855-1862.

44. Tanida S, Inoue N, Kobayashi K, et al. Adalimumab for the treatment of Japanese patients with intestinal Behçet's disease. Clin Gastroenterol Hepatol 2015;13:940-948.e3.

45. Hibi T, Hirohata S, Kikuchi H, et al. Infliximab therapy for intestinal, neurological, and vascular involvement in Behcet disease: efficacy, safety, and pharmacokinetics in a multicenter, prospective, open-label, single-arm phase 3 study. Medicine (Baltimore) 2016;95:e3863. doi: 10.1097/MD.0000000000003863.

46. Van Assche G, Magdelaine-Beuzelin C, D'Haens G, et al. Withdrawal of immunosuppression in Crohn's disease treated with scheduled infliximab maintenance: a randomized trial. Gastroenterology 2008;134:1861-1868.

47. Schnitzler F, Fidder H, Ferrante M, et al. Long-term outcome of treatment with infliximab in 614 patients with Crohn's disease: results from a single-centre cohort. Gut 2009;58:492-500.

48. Colombel JF, Sandborn WJ, Reinisch W, et al. Infliximab, azathioprine, or combination therapy for Crohn's disease. N Engl J Med 2010;362:1383-1395.

49. Dassopoulos T, Sultan S, Falck-Ytter YT, Inadomi JM, Hanauer SB. American Gastroenterological Association Institute technical review on the use of thiopurines, methotrexate, and antiTNF-alpha biologic drugs for the induction and maintenance of remission in inflammatory Crohn's disease. Gastroenterology 2013;145:1464-1478.e5. 
50. Matsumoto T, Motoya S, Watanabe K, et al. Adalimumab monotherapy and a combination with azathioprine for Crohn's disease: a prospective, randomized trial. J Crohns Colitis 2016;10:1259-1266.

51. Zallot C, Peyrin-Biroulet L. Deep remission in inflammatory bowel disease: looking beyond symptoms. Curr Gastroenterol Rep 2013;15:315.

52. Lee HJ, Kim YN, Jang HW, et al. Correlations between endoscopic and clinical disease activity indices in intestinal Behcet's disease. World J Gastroenterol 2012;18:5771-5778.

53. Yim SM, Kim DH, Lee HJ, et al. Mucosal healing predicts the long-term prognosis of intestinal Behçet's disease. Dig Dis Sci 2014;59:2529-2535.

54. Naganuma M, Iwao Y, Inoue N, et al. Analysis of clinical course and long-term prognosis of surgical and nonsurgical patients with intestinal Behçet's disease. Am J Gastroenterol 2000;95:2848-2851.
55. Jung YS, Cheon JH, Park SJ, Hong SP, Kim TI, Kim WH. Clinical course of intestinal Behcet's disease during the first five years. Dig Dis Sci 2013;58:496-503.

56. Chung MJ, Cheon JH, Kim SU, et al. Response rates to medical treatments and long-term clinical outcomes of nonsurgical patients with intestinal Behçet disease. J Clin Gastroenterol 2010;44:e116-e122. doi: 10.1097/MCG.0b013e3181c8a50f.

57. Moon CM, Cheon JH, Shin JK, et al. Prediction of free bowel perforation in patients with intestinal Behçet's disease using clinical and colonoscopic findings. Dig Dis Sci 2010;55:29042911.

58. Iida M, Kobayashi H, Matsumoto T, et al. Postoperative recurrence in patients with intestinal Behçet's disease. Dis Colon Rectum 1994;37:16-21.

59. Jung YS, Yoon JY, Lee JH, et al. Prognostic factors and long-term clinical outcomes for surgical patients with intestinal Behcet's disease. Inflamm Bowel Dis 2011;17:1594-1602. 